\title{
TERRITORIALIDAD Y LAUDO FORENSE. EL CASO "MISIÓN ESTEROS” (FORMOSA, ARGENTINA)
}

\author{
Territoriality and Forensic award. The case of "Misión Esteros" \\ (Formosa-Argentina)
}

\author{
Bárbara Desántolo; Guillermo N. Lamenza; Gabriel O. Balbarrey; \\ Virginia Ramallo; Carlos De Feo; Horacio A. Calandra; \\ José A. Braunstein; Susana A. Salceda
}

\section{Resumen}

En los últimos años los pueblos indígenas de América Latina vienen demandando al Estado el reconocimiento legal de las tierras que ellos han habitado tradicionalmente. En Argentina, un ejemplo de ello lo constituye la solicitud realizada al Laboratorio de Antropología Forense del Museo de La Plata por la Comunidad Wichi "Pajarito" para realizar un peritaje forense en un antiguo cementerio en el Paraje Esteros (Formosa) a fin de legalizar y reivindicar sus derechos legítimos sobre las tierras que ocuparan en la antigua Misión. En este marco se acordó un plan de trabajo que consistió en la excavación arqueológica de inhumaciones, el relevamiento somatométrico de la población actual y la obtención de muestras de ADN antiguo y actual. Los restos óseos exhumados correspondientes a un individuo fueron trasladados temporalmente al Laboratorio de Antropología Forense del Museo de La Plata. En el análisis ulterior se aplicaron técnicas bioantropológicas macro y microscópicas para la estimación de edad y sexo; análisis métrico para estimar la estatura, asimismo fueron utilizadas técnicas moleculares para determinar su filiación.

$<$ Antropología forense $><$ pueblos originarios $><$ territorialidad $>$

\begin{abstract}
In recent years, the indigenous peoples of Latin America are suing the State legal recognition of the lands they have traditionally inhabited. In Argentina, an example of this is the request made to the Laboratory of Forensic Anthropology from the Museum of La Plata by the Wichi Community "Pajarito". This community requested a forensic investigation at the old cemetery from Misión Esteros (Formosa, Argentina) to claim and legalize their legitimate rights over the lands they occupied. In this context, it was agreed a work plan regarding archaeological excavation of burials, somatometric survey from current population and obtaining past and present DNA samples. As a result, the skeletal remains exhumed of an individual were temporarily moved to the Laboratory. Finally, macro and microscopic bioanthropological techniques were applied to estimate age and sex, metrics analysis were utilized to estimate height, and molecular techniques were also used to determine filiation.
\end{abstract}

$<$ Forensic anthropology $><$ native peoples $><$ territoriality $>$ 


\section{Introducción}

En los últimos años los pueblos indígenas de América Latina vienen demandando a los Estados nacionales el reconocimiento legal de las tierras que ellos han habitado tradicionalmente. En Argentina, un ejemplo de ello lo constituye la solicitud realizada al equipo de antropología forense del Museo de La Plata por la Comunidad Wichi "Pajarito" (Afwenchelhos). La misma se enmarca dentro de la problemática jurídica de "tierras indígenas" y grafica claramente la relación existente entre diversas disciplinas antropológicas integradas por su orientación pública. El peritaje forense involucraba la excavación arqueológica del antiguo cementerio en el Paraje Esteros, localizado sobre el Río Bermejo, al sudoeste del poblado Juan G. Bazán en la provincia de Formosa. Este permitiría aportar evidencias tendientes a legalizar y reivindicar sus derechos legítimos sobre las tierras que ocuparan en la antigua Misión. Esta solicitud fue motivada a partir de la institución del le-wit'ole que comprometía a la comunidad a retornar a su primer asentamiento sedentario ${ }^{1}$ y fue viabilizada a través del Centro del Hombre Antiguo Chaqueño ubicado en la Localidad de Las Lomitas, Formosa (CHACO-CONICET) dirigido por el Dr. José Braunstein.

Esta presentación forma parte de la respuesta del sector científico a los requerimientos de la comunidad y se enmarca, en general, en el criterio que los conceptos expuestos conforman una relación justa y equilibrada entre comunidades indígenas e investigadores y, en particular, en una situación legal de litigio en el que se entrelazan aspectos legales y éticos.

Los aportes que contribuyen a fundamentar la pertenencia ancestral surgen del accionar investigativo de ramas disciplinares conexas, y a los efectos de documentar y avalar académica y legalmente las actividades a desarrollar, se conformó un equipo interdisciplinario (arqueólogos, etnógrafos, bioantropólogos, genetistas, abogados y documentalistas) que se integra para llevar a cabo el siguiente laudo forense.

Dado que el uso de procedimientos técnicos propios de las disciplinas participantes, generan cuestiones ético-legales relacionados con el acervo cultural de las comunidades involucradas, en el presente caso se procedió a formalizar un acuerdo entre las partes manifestando el mutuo conocimiento y consentimiento respecto a las actividades a realizar, en el marco de la normativa vigente.

En este contexto se acordó un plan de trabajo que consistió en la excavación arqueológica de inhumaciones, el relevamiento somatométrico de la población actual y la obtención de muestras de ADN antiguo y actual.

Para una mejor comprensión presentaremos la información en dos acápites: una primera parte en donde se describe el trabajo de campo y una segunda parte donde se detalla el trabajo realizado en el laboratorio y los resultados obtenidos del presente estudio.

\footnotetext{
${ }^{1}$ Para una descripción detallada del proceso de solicitud por parte de la comunidad se recomienda ver Braunstein (2012).
} 


\section{Trabajo de Campo}

Las actividades de campo se desarrollaron dentro del espacio delimitado por la Antigua Misión Esteros. Este espacio conforma un territorio donde actualmente se encuentran asentadas 8 familias, instaladas en viviendas terminadas y en ejecución, además de una estructura central de uso comunitario para albergar reuniones de distinto carácter (recepción de viajeros, entre otras). La construcción de las mismas y el uso del espacio reflejan las de un típico asentamiento espontáneo en un marco biogeográfico silvestre y etnográficamente reconocible. Extendiéndose del área de habitación y respetando los límites tradicionales de dicho territorio se encuentran las áreas reconocidas para el emplazamiento de espacios formales de entierro.

Una vez identificado uno de los espacios potenciales para el establecimiento de un lugar de inhumación, se procede a las tareas de excavación arqueológica mediante la utilización de una metodología estándar de actual vigencia dentro de la disciplina. De esta manera se procede a limpiar la superficie del terreno dando especial significación a los sectores indicados por miembros de la comunidad avezados en las prácticas de entierro. Como resultado se identificó un madero que integraba la cruz de una sepultura en estado fragmentario. La práctica tradicional también puede incluir la señalización de la tumba con un tarro o botijo de cerámica.

Posteriormente se procede a delimitar la zona de excavación y se realiza un planteo de cuadriculas (Figura 1). Se comienza a excavar la cuadrícula A de 2x2m. La tarea se realiza diferenciando en niveles artificiales de $0,10 \mathrm{~m}$ contemplando las irregularidades que plantea la estratigrafía natural.

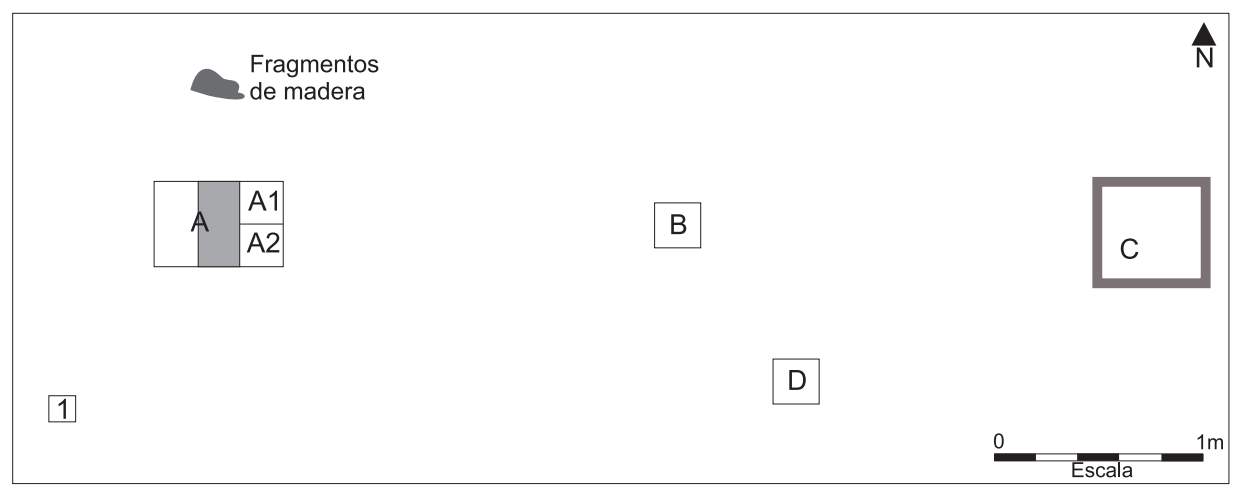

Figura 1. Esquema en planta del área excavada.

Para proceder a la excavación se tiene en cuenta las consideraciones realizadas por los miembros de la comunidad en cuanto a las prácticas tradicionales como ser la profundidad posible de entierro entre 1,5 y 2 metros de profundidad y la costumbre de realizar entierros directos, con el cadáver envuelto en una manta o frazada, extendido, decúbito dorsal y con la cabeza mirando al Oeste. El sedimento retirado es tamizado en zaranda de malla fina. No encontrándose evidencias de actividad antrópica pasada 
se decide ampliar el perímetro de la cuadrícula con la finalidad de abarcar mayor superficie. Se diagraman y ejecutan dos cuadrículas en el borde Este de 1x1m las que se denominaron A1 y A2. Se excavan, resultando infértiles en lo que a restos humanos refiere. Por ello se proyecta la ejecución de un pozo de sondeo de $0,5 \times 0,5 \mathrm{~m}$. ubicado transversalmente y a $4 \mathrm{~m}$ de la cuadrícula A, en dirección Sudoeste. Excavado el testigo y resultando infructuosa la búsqueda se proyecta una segunda cuadrícula $\mathrm{B}$ ubicada a 10m al Este de la cuadrícula A y ejecutada cubriendo una superficie de 1x1m. Simultáneamente y a partir del reconocimiento de una pequeña elevación, novedosa como rasgo indicador, se proyecta una tercera cuadrícula $\mathrm{C}$ ubicada al Este de la cuadrícula B y a una distancia de $10 \mathrm{~m}$ aproximadamente. Mientras la cuadrícula B resulta infértil, en la $\mathrm{C}$ comienzan a aparecer, en el primer nivel, elementos indicadores de restos óseos lo cual motiva que, previo a su excavación sistemática, los miembros de la comunidad procedan a orar (Figura 2). La excavación de la cuadrícula $\mathrm{C}$ se resume en el hallazgo de restos óseos entre $\operatorname{los} 0,10$ y $0,60 \mathrm{~m}$ de profundidad. Se grafica su ubicación estratigráfica, identifica y se embolsa. En términos generales, su tamaño y estado muy fragmentario los hace indeterminables. Se infiere que se trata de partes de elementos óseos de origen animal, sin correspondencia individual, criterio que se ajustará posteriormente en laboratorio.

Se procede con el mayor detalle y continuidad profundizando los niveles y registrando todos los hallazgos y rasgos particulares. A $0,90 \mathrm{~m}$ surgen claras evidencias determinantes de la presencia de restos óseos humanos correspondientes a la sínfisis púbica de la cintura pélvica (Figura 3). Se adecua la excavación a las evidencias en razón de los hallazgos observados, planificando y ejecutando tareas complementarias (relevamiento gráfico, fotográfico y fílmico del hallazgo). El nivel inferior real de entierro se establece a $1.10 \mathrm{~m}$ de profundidad (medido desde el nivel 0 hasta la región occipital del cráneo) estableciendo su ubicación tridimensional. Se realiza un pedestal de entierro a fin de exponer los restos y tener una visión del conjunto y de la asociación de partes. Así se puede identificar que se trata de un entierro primario de esqueleto completo cuyas piezas óseas se encuentran en posición anatómica natural. Inhumado en posición extendida, decúbito dorsal (boca arriba) y orientado en dirección $\mathrm{NE}-\mathrm{SO}$ (cabeza hacia el NE). Asociados al material esqueletario se observa restos de tela, los que se corresponden probablemente con una envoltura mortuoria tal cual refieren los miembros de la comunidad acompañantes (se toma una muestra para realizar análisis de las fibras). Asimismo y hacia el lateral derecho se observan restos de un pieza metálica también, que a juicio de los paisanos sería "su jarro". La observación in situ de la cavidad oral entreabierta, insinúa la presencia de un sedimento de coloración diferente al conjunto que lo rodea que reafirma la decisión de levantar la pieza en su matriz para una ulterior toma de muestra y análisis sedimentológico.

De forma simultánea a la excavación de la cuadrícula $\mathrm{C}$ se ejecuta la realización de una cuadrícula $\mathrm{D}$ a tres metros de la $\mathrm{B}$ con orientación diagonal Sudeste. Se delimita una cuadrícula de 1x1m y se procede a su limpieza y nivelación. 
Folia Histórica del Nordeste, N$^{0} 21$ (Resistencia, 2013) IIGHI, IH - CONICET, UNNE

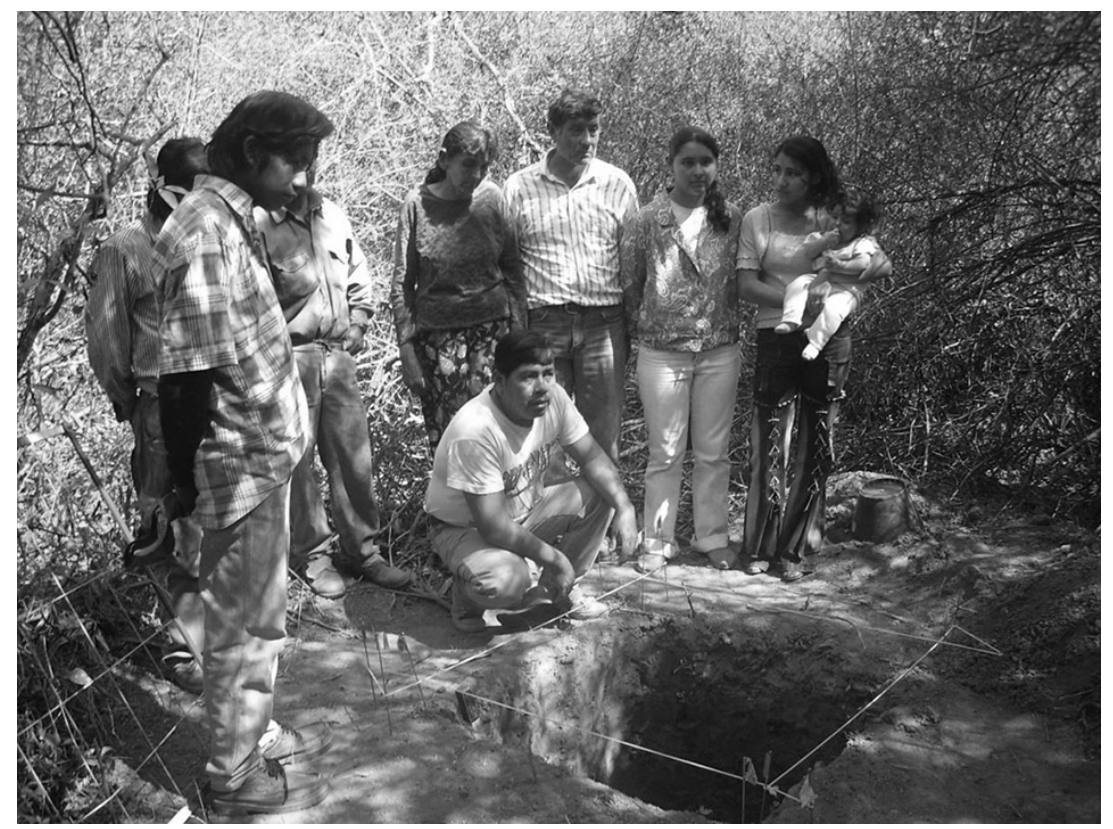

Figura 2. Oración previa a la exhumación de restos óseos.

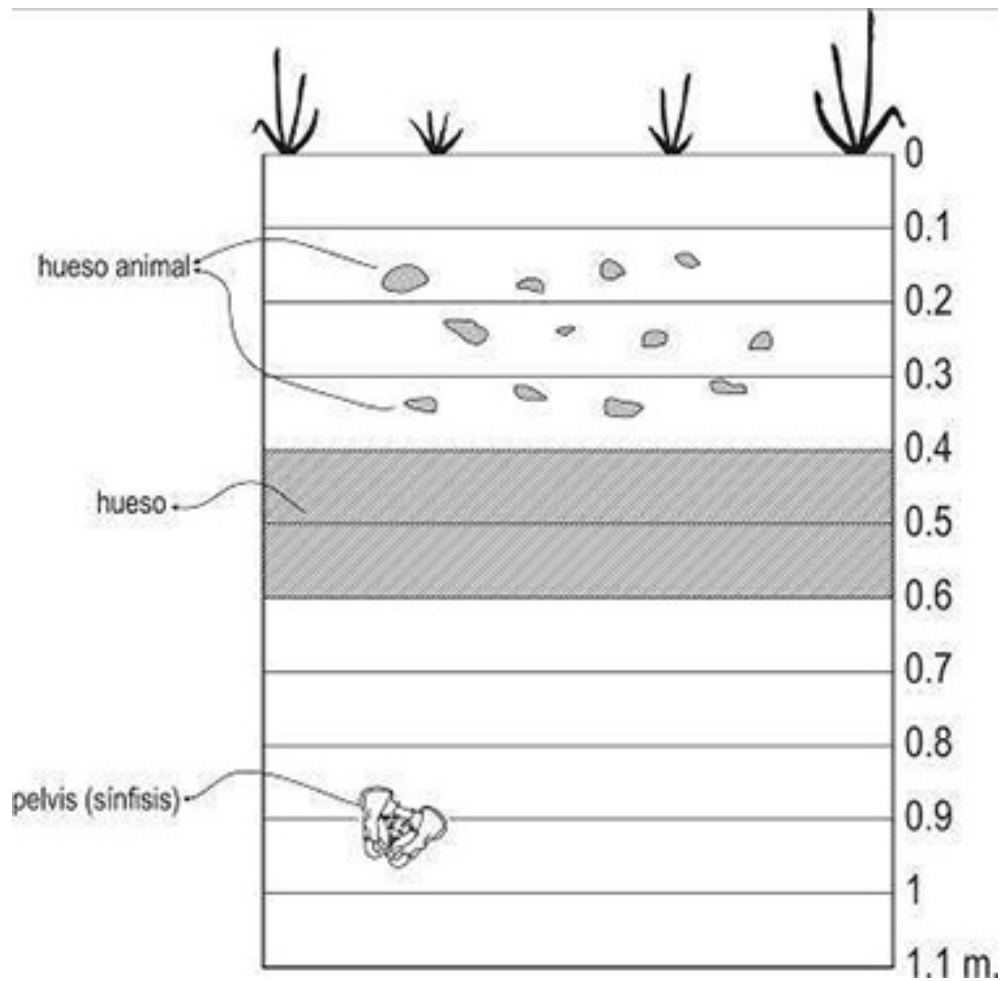

Figura 3. Perfil estratigráfico de la Cuadricula C. 
Se excava por niveles artificiales de $0,10 \mathrm{~m}$, capa a capa hasta $10 \mathrm{~s} 0,80 \mathrm{~m}$ de profundidad, resultando su contenido infértil. Otros miembros del equipo, de manera complementaria a las excavaciones arqueológicas y con el propósito de establecer nexos entre ancestros y descendientes, desarrollaron tareas vinculadas con el relevamiento somatométrico entre los niños de la comunidad y la toma de muestras de saliva para determinación de $\mathrm{ADN}$ al total de los pobladores.

\section{Trabajo en el Laboratorio}

Las muestras obtenidas y los restos recuperados fueron trasladados temporalmente al Laboratorio de Antropología Forense (División Antropología, Museo de La Plata) para su ulterior análisis previo acuerdo de partes. Además, se solicitó autorización para extraer tejido óseo y una pieza dentaria a ser analizadas comparativamente con los resultados de ADN sobre muestras de saliva obtenidas en población actual. Las evidencias sedimentarias mostraron alteración de la estratigrafía natural con irregularidad manifiesta de los niveles naturales de depositación por intrusión de otros sedimentos traslocados.

Por otra parte las evidencias no sedimentarias demostraron lo siguiente,

1. Los restos óseos fragmentarios, mal preservados, probablemente pertenecen al Orden Rodentia y las fracturas óseas observadas no indican acción antrópica.

2. Los restos de tela de tono pardo oscuro probablemente dispuesta como envoltura mortuoria tal cual refieren los miembros de la comunidad acompañantes. Su análisis detallado indica algodón de hilado fino y teñido, tejido en telar, de trama abierta similar a la tela denominada arpillera. En uno de sus bordes presenta terminación elaborada con delgadas hebras trenzadas de color verdoso, también de algodón. Puede suponerse que estos textiles no formaron parte del conjunto de bienes ergológicos realizados tradicionalmente por los wichí, sino que provendría de bienes adquiridos transculturalmente.

3. Restos metálicos mínimos ubicados hacia el lateral derecho del sujeto inhumado. La tradición wichí relata la presencia frecuente de piezas de metal (jarros, ollas, baldes) en desuso dispuestas sobre la superficie del espacio fúnebre y sobre una pequeña altura como indicadoras de localización sepulcral. Tal cual distintos caracteres (cruz, monolito, apacheta, escultura, banderas, cintas de colores, otros) en otras sociedades y con diferente grado de complejidad reflejan esta función.

4. La presencia de un sedimento de coloración diferente al conjunto que lo rodea observado in situ en la cavidad oral entreabierta, requirió de análisis específicos a fin de determinar sus características particulares. Se comprueba así que el material contenido en la boca presentaba aspectos constitutivos y estructurales diferenciadores de la matrix sedimentaria continente. Pruebas de detalle tendientes a evaluar la composición química no arrojaron resultado indicativo, aunque de las entrevistas con miembros de la comunidad se sugiere que en tiempos pasados era frecuente colocar en la boca del individuo sepultado algunas hojas de coca. 


\section{Análisis Osteológico}

Los elementos óseos recuperados presentan estricta correspondencia individual y responden al siguiente inventario: 1) Cráneo completo, 2) esternón, 3) costillas [24], 4) vértebras: [7] cervicales, [12] torácicas y [5] lumbares, 5) sacro, 6) clavícula derecha e izquierda, 7) escápula derecha e izquierda, 8) coxal derecho e izquierdo, 9) húmero derecho e izquierdo, 10) cúbito derecho e izquierdo, 11) radio derecho e izquierdo, 12) carpianos [16] derechos e izquierdos, 13) metacarpianos [10] derechos e izquierdos, 14) falanges [28] derechas e izquierdas, 15) fémur derecho y fémur izquierdo, 16) tibia derecha e tibia izquierda, 17) peroné derecho e peroné izquierdo, 18) rótula derecha y rótula izquierda, 19) tarsianos [14] derechos e izquierdos, metatarsianos [10] derechos e izquierdos, 20) falanges [28] derechas e izquierdas.

\section{Estimación de la edad probable}

La estimación de edad a la muerte en restos esqueletarios incluye la observación de ciertos caracteres morfológicos diagnósticos, su comparación con la información registrada respecto a los cambios ontogenéticos para poblaciones actuales de edad a la muerte conocida y la estimación de algunas fuentes de error ligadas a la variabilidad interpoblacional. Analizadas morfoscópica y morfométricamente las piezas esqueletarias diagnósticas disponibles se concluye que:

- Esqueleto postcraneal: El grado de fusión de las epífisis con sus correspondientes diáfisis en huesos largos del esqueleto postcraneano presenta una secuencia cronológica con correspondencia auxológica durante la vida de un individuo, siendo mayor la actividad epifisial entre los 15 y los 23 años. Esta fusión es progresiva y usualmente se clasifica en: no fusionada (no unión), 1/4 unida, 1/2 unida, 3/4 unida, fusión total (unión completa) con variaciones leves entre individuos según sexo (White y Folkens, 2005). En este caso, el grado de fusión en todas las epífisis es total, lo cual habilita con precisión asignar categoría adulto al individuo analizado. Además, y teniendo en cuenta la fuerte correlación de la edad con cambios morfológicos específicos en la carilla auricular del ilion (Lovejoy et al., 1985) se procedió a analizar dicha estructura. Ambos coxales se corresponden con la Fase V, cuya edad cronológica oscila entre 40 y 44 años.

- Cráneo: Complementariamente, se tomaron en cuenta dos indicadores de edad observables en cráneo:

a) Desgaste dentario. El uso de este rasgo para estimar la edad se fundamenta en que la abrasión resultante de la masticación en la dentición permanente avanza en forma continua durante la vida de un individuo, con las precauciones derivadas de su variabilidad inter e intrapoblacional y de su labilidad ante factores medioambientales y culturales. En este caso, las piezas dentarias disponibles presentan un desgaste que se corresponde con las Fases H - I (Lovejoy, 1985) con edad estimada entre 40-50/45-55 años respectivamente. 
b) El estado de las suturas craneanas es un rasgo que, a pesar de su gran variabilidad individual y dimórfica, permite la estimación de la edad a partir de su grado de sinostosis u obliteración. Tal estado se relevó en vista exocraneana, según método propuesto por Meindl \& Lovejoy (1985). También desde este criterio se reafirma la pertenencia del individuo a la categoría adulto.

\section{Estimación del sexo probable}

Para la determinación se escogieron aquellas piezas que por su valor diagnóstico (Buikstra y Ubelaker, 2004; White y Folkens, 2005) permiten estimar con mayor precisión el sexo en individuos adultos. Se presentan seguidamente las valoraciones resultantes del análisis realizado ya que los caracteres morfológicos aportan suficiente información para una certera diagnosis de pertenencia genérica. Se siguieron las recomendaciones propuestas en el "Workshop of European Anthropologists" (W.E.A) (Ferembach et al. 1980). La metodología a aplicar se basa en la ponderación de aquellos rasgos morfológicos más diagnósticos para pelvis y cráneo.

- Pelvis: Se relevaron los rasgos con mayor poder discriminatorio y se calculó el grado de sexualidad resultando masculino por presentar: 1. sulcus praeauricularis presente en forma de traza, 2. incisura ischiadica mayor en forma de V, 3. angulus pubis agudo, no comparable, 4. arcus compositus con curva única, 5. os coxae alto, estrecho, 6. foramen obturatum ovalado, 7. Corpus ossis ischii ancho, 8. crista iliaca en forma de S neta, 9. fossa iliaca alta y estrecha, 10. pelvis mayor no comparable, 11. pelvis minor no comparable.

- Cráneo: Procediendo del mismo modo que para pelvis, el análisis multivariado revela que también el cráneo presenta rasgos que permiten adscribirlo al género masculino. Ellos son: 1) glabella marcada, 2) processus mastoideus grande, 3) superficie del planum nuchale con línea nucal superior grande y cresta occipital desarrollada, 4) processus zigomaticus alto y fuerte, 5) Arcus superciliaris marcado, 6) tubera frontalia et parietalia ausente, 7) protuberancia occipitales externa fuerte, 8) inclinatio frontalis fuertemente huidiza, 8) os zigomaticum, alto con superficie irregular, 9) forma orbitae cuadrada con margo supraorbitalis fuertemente redondeado, 10) mandíbula de aspecto robusto, 11) mentum fuerte con protuberancia bilateral, 12) angulus mandibulae con rugosidad y retroversión notable.

Este diagnóstico fue corroborado a través del cálculo de la función discriminante propuesta por Giles y Elliot (1963) y Giles (1968). El valor obtenido (3005.74) ubica claramente a la pieza en la categoría sexo masculino (Valor discriminante $=2676,39$ ).

- Huesos largos (fémur)

Numerosos estudios métricos sobre el esqueleto han provisto datos acerca de las diferencias en tamaño involucradas en el dimorfismo sexual, con una precisión en la estimación entre el 80 y 90 \% (Steele y Bramblett, 1989). Entre las variables métricas simples utilizadas, el diámetro vertical de la cabeza femoral es buen indicador de sexo. 
La línea que actúa como punto de sección para tal diagnosis es aquella ubicada entre los valores 45 y $46 \mathrm{~mm}$. Por encima de los $46 \mathrm{~mm}$ correspondería al sexo masculino y por debajo al femenino, siendo la media para el sexo masculino $48 \mathrm{~mm}$ y para el femenino 41,7 mm y estableciéndose una franja de indefinición genérica de $2 \mathrm{~mm}$ (Stewart, 1979; Steele y Bramblett, 1989). En este caso ambos fémures con $46 \mathrm{~mm}$ de diámetro vertical máximo de la cabeza corresponden a un individuo de sexo masculino. El resultado obtenido fue contrastado con el cálculo de la función discriminante propuesta por Giles (1970). El valor obtenido (3312.08) ubica a la pieza en la categoría sexo masculino (Valor discriminante $=3040.08)$.

\section{Aportes bioantropológicos para la identificación}

La estimación de la morfología craneana se realizó a través del relevamiento morfométrico pormenorizado del cráneo (Buikstra y Ubelaker, 1994). El cálculo de índices indicadores de forma permiten caracterizar al individuo como sigue: cabeza de capacidad media (1373,55 según fórmula de Lee y Pearson), alargada en sentido anteroposterior (Índice Craneano Horizontal $=70.33$ ), alta en relación a la longitud (Índice Craneano Vértico-Longitudinal $=75.27$ ) y alta respecto a la anchura (Índice Craneano Vértico-Transversal $=107.03$ ), de frente ancha (Índice Fronto-Parietal $=$ 85.16 ) con crestas temporales intermedias (Índice Frontal Transversal $=87.15$ ), con región maxilar no saliente (Índice Gnático $=102.04$ ), cara baja y ancha (Índice Facial Superior $=44.93$ ), nariz alta y estrecha (Índice Nasal $=40.71$ ), órbitas medias (Índice Orbitario $=83.33$ ), arcada alveolar superior ancho (Índice Arcada Alveolar $=116.00) \mathrm{y}$ paladar ancho y corto (Índice Palatino $=97.56$ ).

\section{Estimación de la estatura}

La relación entre la longitud de los huesos largos y la estatura del individuo, a todas las edades, ha servido a los osteólogos para reconstruirla a partir de valores métricos obtenidos en diferentes elementos óseos post craneanos (White y Folkens, 2005). La estimación de la estatura se realizó a partir del fémur izquierdo utilizando la fórmula de Trotter (1970).

Trotter, 1970

$$
\begin{gathered}
\text { Masculino } 2.38 \text { x (fémur) }+61.41=\text { estatura }+/-3.27 \\
2.38 \times 43.7+61.41=\mathbf{1 6 5 . 4 1 6}(162.14-168.68)
\end{gathered}
$$

\section{Patologías}

Se observa en la epífisis distal de ambas tibias un reborde anterior, en particular en la carilla articular del astrágalo, más desarrollado en el lateral derecho. A su vez, el astrágalo presenta exostosis superior en la zona articular con la tibia. 
En el esqueleto axial se evidencia leve sindesmofitos en el sacro hacia la quinta vértebra lumbar y excrecencias óseas, llamadas osteofitos, en vértebras de la región dorsal y lumbar. Todos estos indicadores están asociados a patologías articulares producto del envejecimiento (cambios degenerativos derivados de edad avanzada), agudizados por los estilos de vida (pueblos deambuladores).

\section{Análisis Molecular}

Generalidades

Todas las personas heredamos de nuestros padres la información que nos hace únicos, almacenada en el ADN (Acido Desoxirribonucleico) dentro de cada célula de nuestro cuerpo y forma lo que llamamos genoma. Resulta evidente en nuestros rasgos, el cabello o el tipo y color de ojos. Además, también compartimos con ellos, con nuestros hermanos y con todos los parientes biológicos parte de la información que caracteriza a cada familia, porque se transmite de generación en generación. A lo largo del tiempo, se han desarrollado muchos estudios sobre el ADN en distintos laboratorios del mundo. Con esta información fue posible conocer cómo las familias han viajado ocupando diferentes regiones, cómo se han asentado las distintas comunidades o cómo se han desplazado a otro lugar. El ADN cuenta la historia de los seres humanos: si se toma una muestra de una persona, se puede conocer de qué parte del planeta provienen sus antepasados.

\section{Muestreo y obtención de datos}

\section{- Población Actual}

Durante la estadía en la localidad se realizaron entrevistas para completar datos de cada una de las familias residentes. Las muestras biológicas se tomaron por salivación directa, completando un total de 19 representativas del posible total de ancestros mujeres y varones de la comunidad. Una vez en el laboratorio, a partir de la saliva se obtuvo el ADN y se almacenó en el banco de muestras del Instituto Multidisciplinario de Biología Celular (IMBICE)2. Con la información dada por los donantes en las entrevistas, se construyeron árboles familiares.

Inicialmente, se trabajó con las 9 muestras de varones. A diferencia de las mujeres, todos los hombres reciben de su padre una porción de ADN que determina su sexo y es heredada y compartida por todos los varones. Es en esta porción donde se buscaron semejanzas con los abuelos y bisabuelos y otros antepasados paternos distantes en el tiempo, una relación entre las personas que llamamos linaje. Se deseaba conocer si los linajes de estos donantes se originaron en América y también se usaron otros ensayos de laboratorio, llamados microsatélites.

\footnotetext{
${ }^{2}$ Instituto Multidisciplinario de Biología Celular (La Plata. Buenos Aires-Argentina)
} 


\section{- ADN del individuo exhumado}

Para complementar los datos de la población actual con aquellos que pudieran obtenerse del cuerpo recuperado en la excavación de campo, se solicitó el apoyo de profesionales específicos. La extracción de ADN a partir del material óseo se realizó en el Laboratorio de Antropología Molecular, Programa de Genética Humana, Instituto de Ciencias Biomédicas, Facultad de Medicina, Universidad de Chile, Santiago, -Chile a cargo del Dr. Mauricio Moraga.

El ADN fue extraído de dos muestras pertenecientes a un mismo individuo, correspondientes a un fragmento de diáfisis de un hueso largo y una pieza dental. Se realizó análisis de haplogrupos mediante la técnica de PCR-RFLP y se analizaron las regiones HV1 y HV2 mediante secuenciación directa.

\section{Resultados}

\section{Síntesis morfológica interpretativa}

1. Se trata de restos óseos humanos correspondientes a un único individuo (NMI =1).

2. Se trata de un individuo de sexo masculino, de 45 años de edad media estimada.

3. El individuo presenta una cabeza de capacidad media, alargada en sentido anteroposterior y alta, con región frontal ancha, maxilar no saliente, cara baja y ancha acompañada de nariz alta y estrecha, órbitas medias, arcada alveolar superior ancha y paladar ancho y corto.

4. La estatura estimada es de $165.41 \mathrm{~cm}$.

5. Las patologías observables componen la etiología del proceso natural del envejecimiento. Desde una interpretación generalizante, todas estas características principalísimas permiten inferir ancestría en poblaciones de raíz chaqueña, a juzgar por la articulación de rasgos cuali y cuantitativos compatibles y caracterizantes de los actuales pueblos originarios de esta región.

\section{Síntesis molecular interpretativa}

\section{- Población actual}

1. Todos los donantes varones de la comunidad representan linajes nativos de América. 2. En cuanto a los microsatélites, estos permiten identificar una persona y asociar esos datos a la identificación a partir de apellidos. En las 9 muestras, se encuentran 3 apellidos diferentes y esta misma variedad se observa en los datos de $\mathrm{ADN}$ establecidos hasta el momento.

\section{- ADN del individuo exhumado}

Se obtuvieron secuencias para todos los fragmentos amplificados tanto de los DNAs extraídos de hueso como de los de diente. Los polimorfismos presentes en las zonas de traslape entre los fragmentos amplificados fueron idénticos y las secuencias obtenidas con los dos juegos de partidores utilizados fueron iguales. De igual modo 
las secuencias obtenidas con partidores directos y reversos fueron idénticas. Las dos muestras arrojaron la misma secuencia. El individuo es portador de un linaje mitocondrial definido por la presencia de mutaciones. El linaje mencionado es parte del haplogrupo amerindio A2, y la presencia de la mutación 16051 define un subhaplogrupo por el momento sólo conocido entre poblaciones aborígenes del Gran Chaco argentino. En efecto, este sub-haplogrupo ha sido encontrado en Wichís y Tobas de Chaco y Formosa (Cabana et al., 2006) y en Mocovíes de Santa Fé (Tamm et al., 2007). Investigadores del IMBICE lo han encontrado también en Wichís y Chorotes de Salta (C. Bravi, resultados inéditos), pero estaría ausente en otras poblaciones del Chaco paraguayo y boliviano como Ayoreo y Lengua (Dornelles et al., 2004; C. Bravi, resultados inéditos). Hasta donde se conoce, este particular subhaplogrupo no ha sido informado en unas 5000 muestras de poblaciones indígenas y mestizas del resto de Sudamérica.

\section{Conclusiones}

Tal como se desprende a partir de los estudios realizados se constatan las siguientes conclusiones:

- Localización en el ámbito regional y vecinal de comunidades Wichí con referencia en la literatura etnohistórica.

- Precisa localización y señalización de la tumba en correspondencia con el conocimiento tradicional Wichí.

- Práctica inhumatoria (emplazamiento, disposición, ajuar, entre otros) concordante con la actual modalidad de proceder en comunidades Wichí.

- Los rasgos morfodiagnósticos obtenidos a partir del individuo exhumado se corresponden con las características bioantropológicas de poblaciones chaqueñas actuales.

- Total concordancia molecular entre los individuos actuales y el resto inhumado. Las cuales, sin lugar a dudas, pueden identificar al resto exhumado como ancestro de la población actual aludida.

A partir de la comunicación de esta experiencia se integra al quehacer científico un campo de acción donde se trabaja de manera conjunta con la comunidad enmarcándose dentro del dominio de una antropología de orientación pública. En este caso particular la participación de antropólogos biólogos, arqueólogos, etnógrafos y genetistas en respuesta a una problemática de tipo jurídico-legal y a pedido de miembros de la etnia Wichi ha permitido aportar elementos determinantes en el proceso de restitución de tierras. La consideración de la vinculación que la comunidad mantiene con sus antiguos espacios de inhumación y así reconocer su pertenencia territorial claramente responde a un cambio positivo hacia una total integración y reconocimiento propios de una sociedad pluriétnica y multicultural. 


\section{Agradecimientos}

Los autores de esta publicación y otros tantos colaboradores, manifiestan su profundo agradecimiento a la comunidad Wichí "Pajarito" por haber depositado en ellos su máxima confianza.

\section{Referencias Bibliográficas}

Braunstein, J. A. 2012. "Tierras indígenas y antropología: facetas múltiples de una alianza "natural"”. En: Maeder, Fantín y Salinas (coordinadores). Estudios y Contribuciones: homenaje a la doctora Norma Cristina Meichtry. Resistencia. Contexto Libros. Pp: 9-43.

Buikstra, J. E; Ubelaker, D. 1994. Standards for Data Collection from Human Skeletal Remains. Arkansas. Archeological Survey Research Serie No 44.

Cabana, G., Andrew Merriwether, D., Hunley, K., Demarchi, D. 2006. "Is the Genetic Structure of Gran Chaco Populations Unique? Interregional Perspectives on Native South American Mitochondrial DNA Variation". Am. J. Phys. Anthropol. 131:10B-119.

Dornelles, C., Battilana, J., Fagundes, N., Freitas, L., Bonatto, S., Salzano, F. 2004. "Mitochondrial DNA and Alu insertions in a genetically peculiar population: The Ayoreo Indians of Bolivia and Paraguay". Am. J. Hum. Biol., 16: 479-488.

Ferembach D, Schwidetzky I, Stloukal M. 1980. "Recommendations for age and sex diagnoses of skeletons". J. Hum. Evol. 9:517-549.

Giles, E., Elliot, O. 1963. "Sex determination by discriminant function analysis of crania". Am. J. Phys. Anthropol. 21:53-68.

Lovejoy, C.O., Meindl, R.S., Pryzbeck, T.R., Mensforth, R.P. 1985. "Chronological metamorphosis of the auricular surface of the Ilium: A new method for the determination of adult skeletal age at death". Am. J. Phys. Anthropol. 68: 15-28.

Lovejoy, C.O. 1985. "Dental wear in the Libben population: Its functional pattern and role in the determination of adult skeletal age at death". Am. J. Phys. Anthropol. 68: 47-56.

Meindl, R.S., Lovejoy C.O. 1985. "Ectocranial Suture Closure: A revised method for the determination of skeletal age at death based on the lateral-anterior sutures". Am. J. Phys. Anthropol. 68:57-66.

Steele, D., Bramblett, C.A. 1989. The Anatomy and biology of the Human Skeleton. Ed. Manufactured in the United States of American. Secon Printing

Stewart, T.D. 1979. Essentials of forensic anthropology. Springfield, Illinois: C.C. Thomas.

Tamm, E., Kivisild, T., Reidla, M., Metspalu, M., Smith, D.G., et al. 2007. "Beringian Standstill and Spread of Native American Founders". PLoS ONE 2(9): e829

Trotter, M. 1970. "Estimation of stature from intact long bones". En T.D. Stewart (ed) Personal identification in mass disasters. Washington DC: Smithsonian Institution Press, pp 7183.

Ubelaker, D. 1978. Human skeletal remains. Excavation, analysis, interpretation. Chicago: Aldine Publishing Company

White, T.D., Folkens, P.A. The human bone manual. Elsevier Academic Press. 